\title{
El Macizo Colombiano como territorio hidrosocial (1990-2018)
}




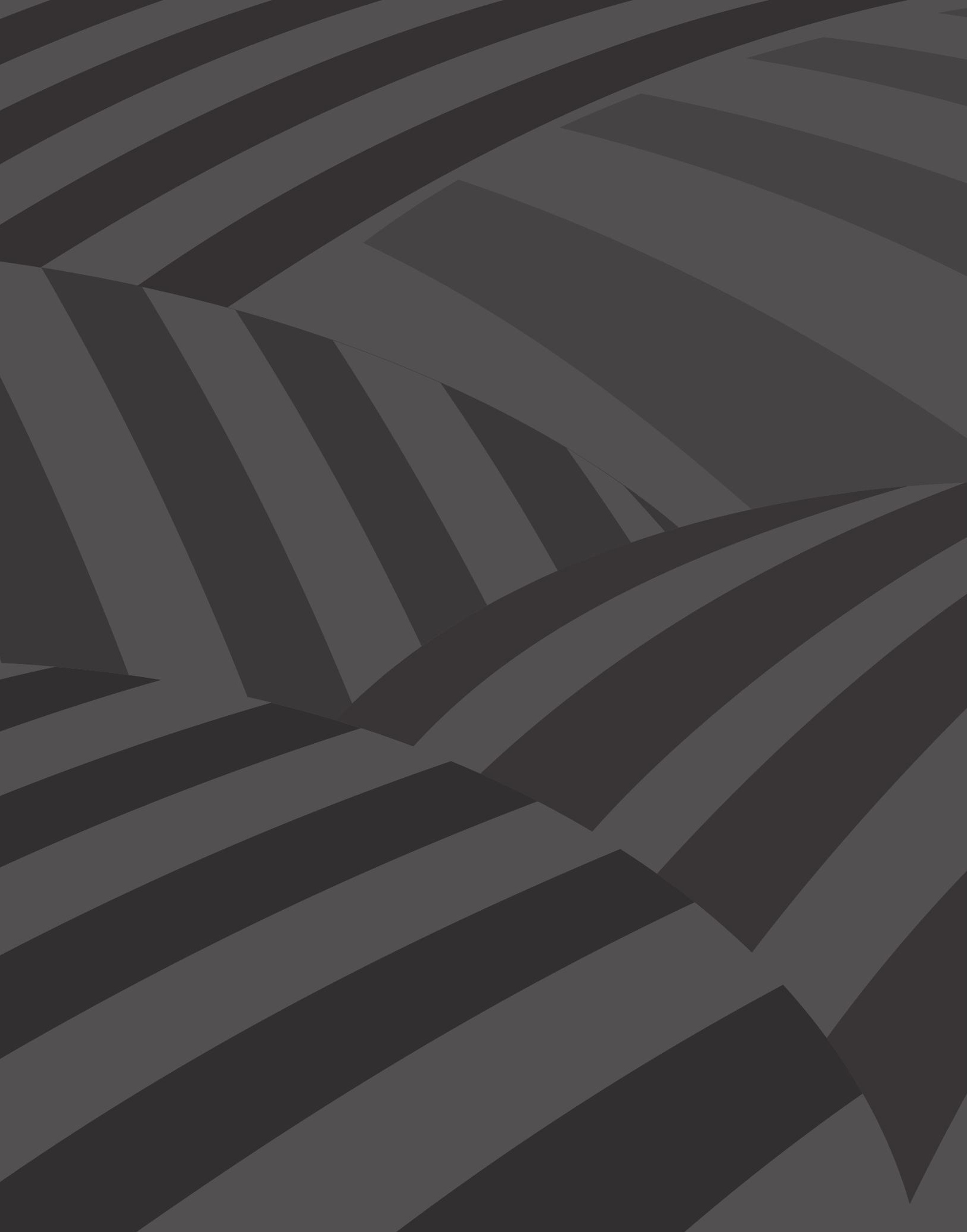




\title{
El Macizo Colombiano como territorio hidrosocial (1990-2018)*
}

\author{
El Macizo Colombiano, que es un territorio \\ de excepcional valor ecológico \\ y reserva estratégica de la humanidad, \\ es una suma de potencialidades y limitantes.
}

(Maciceña, 2000).

Por Camilo Andrés Hernández Barreto**

Resumen: Este articulo busca mostrar cómo se construyen determinadas configuraciones espaciales alrededor del agua, en las que se relacionan las comunidades, la institucionalidad pública, los movimientos sociales, los recursos naturales y los conocimientos ecológicos que dan forma al Macizo Colombiano, como territorio hidrosocial, y otorgan sentido a las territorialidades que interactúan en él. En primer lugar, se define qué es el Macizo Colombiano, y cómo en su definición y redefinición interactúan tres territorialidades que no solo están en tensión constante, sino que se complementan en algunos momentos para dar forma a lo que llamamos territorios hidrosociales (Boelens et al., 2016). La conformación del Macizo como territorio hidrosocial nos permite mostrar estas interrelaciones, donde el eje fundamental es el agua, y a su vez plantear preguntas sobre la configuración del Estado y su relación con la movilización social en esta región.

Palabras clave: territorios hidrosociales, Macizo colombiano, comunidades campesinas, pueblo indígena Yanacona, ecorregión.

\section{The Colombian Massif as a Hydrosocial Territory (1990-2018)}

Abstract: This paper aims to show how the Colombian Massif has been shaped as spatial configuration constructed around water, in which the communities, public institutions, social movements, natural resources and ecological knowledge are related as hydrosocial territory and provide meaning to the territorialities that interact in it. First, we define what the Colombian Massif is, and how the interaction of three territorialities define and redefine this territory constantly, through constant

* El presente artículo es una actualización de un texto presentado originalmente en el primer semestre de 2017, para optar el título de Maestro en Geografía de la Universidad de los Andes, en la modalidad de profundización.

** Historiador con Maestría en Geografía, investigador del Cinep/PPP. 
tension among them, but complement each other, in some moments through the time, to shape what we call hydrosocial territories (Boelens et al., 2016). Understand the Colombian Massif as hydrosocial territory allows us to show this interrelationships, where the fundamental axis is water. At the same time it raise questions about the State configuration and its relation with the social mobilization in this region.

Keywords: Hydrosocial territory, Colmbian Massif, Peasant Communities, Yanacona indigenous people, Ecoregion.

Cómo citar este artículo: Hernández, Camilo (2018). El Macizo Colombiano como territorio hidrosocial (1990-2018). Revista Controversia 210, 203-242.

Fecha de recepción: 15 de febrero del 2018

Fecha de aprobación: 20 de abril de 2018

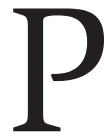

ensar en el Macizo Colombiano como un territorio que constituye "una suma de potencialidades y limitaciones" (Fundecima, 2000) es una forma de resumir las complejas interacciones que dan forma a esta extensa y rica región, productora de recursos considerados estratégicos para la nación, entre los cuales el que más se destaca es el agua. Por esa razón, el objetivo de este escrito es mostrar cómo alrededor del agua se construyen configuraciones territoriales que relacionan a las comunidades, la institucionalidad pública, los movimientos sociales, los recursos naturales y los conocimientos ecológicos que dan forma a distintos territorios, y sentido a las territorialidades que interactúan en el llamado Macizo Colombiano.

Para hacer este ejercicio me basaré en los elementos constitutivos de los "territorios hidrosociales" definidos por Boelens et al. como:

Un imaginario contestatario y la materialización socioambiental de una red multiescalar unida espacialmente, en la que seres humanos, flujos de agua, relaciones ecológicas, infraestructura hidráulica, medios financieros, arreglos administrativo-legales, instituciones culturales y prácticas se definen, alinean y movilizan de forma interactiva a través de sistemas de creencias 
epistemológicas, jerarquías políticas y discursos naturalizadores (Boelens et al., 2016, p. 2)ํ․

Este concepto, aunque amplio ${ }^{2}$, resulta propositivo en la medida en que pone en primer plano al agua como eje articulador de relaciones en el Macizo, a través del ejercicio de poder hídrico, es decir:

las diversas estrategias utilizadas por diversos actores en relación al control del agua, ya sea el Estado, por medio de sus respectivas instituciones, $\mathrm{u}$ otros actores sociales, utilizando para este fin la construcción de infraestructura, la difusión de discursos legitimadores, como el de la búsqueda de eficiencia en la gestión del líquido, políticas de "desarrollo" económico (Rodríguez Sánchez, 2017, p. 29).

Para ver de qué manera operan estas relaciones en el Macizo Colombiano haremos una contextualización del problema y el periodo seleccionados, junto con una breve caracterización de este territorio. Desde la antropología, el territorio ha sido asociado con las identidades, mientras que desde las relaciones internacionales se ha relacionado con la soberanía de los Estados. En el caso de la geografía, este ha sido trabajado desde la sub-disciplina de la geografía política, en la cual también se habla desde la perspectiva de Estado-nación, pero no reduciéndolo únicamente a la soberanía, sino ampliándolo a otro tipo de relaciones

1 Traducción propia:

the contested imaginary and socio-environmental materialization of a spatiality bound multi-scalar network in which humans, water flows, ecological relations, hydraulic infrastructure, financial means, legal administrative arrangements, and cultural institutions and practices are interactively defined, aligned and mobilized through epistemological belief systems, political hierarchies and naturalizing discourses (Boelens, R.; Hoogesteger, J.; Swyngedouw, E.; Vos, J.; \& Wester, P., 2016)

2 Otros autores hablan de configuración hidrosocial, agrupando conceptos como: "ciclo hidro-social” (Swyngedouw, 2009), "perfiles sociometabólicos" (Zanuccoli et al., 2011), "flujos de agua y los flujos de poder" (Meerganz von Medeazza, 2006), “paisajes hídricos” (Budds, 2010).” Ver: Rodríguez Sánchez (2017). 
de poder, que se desagregan en distintas escalas espaciales (Delaney, 2005, p. 4).

Visto así, el territorio parece entenderse como un contenedor de cosas (identidades, relaciones de poder, soberanía, etc.) pero, siguiendo a Delaney (2005), "hablar de territorio no se refiere solo a una manera de nombrar el acto de ordenar objetos dentro de un espacio, sino que tiene además otros fines, que más bien abordan este concepto como un tipo de estrategia, implicada siempre a la comunicación de ciertos tipos de significados y esencialmente clasificatoria, con la función (o al menos el efecto) de reificar formas de identidad y diferencia. A menudo, el territorio es una forma de controlar lo que está adentro, al limitar acceso o excluir a otros. Comparándolo con otro tipo de mecanismos de control, el territorio puede promover, de manera clara y simple, paz, seguridad y orden, al igual que eficiencia y progreso de un grupo social". ${ }^{3}$

Por lo anterior, al hablar de territorio desde la geografía es importante tener en cuenta que este es complejo y dinámico, y por eso mismo, es relacional. Delaney sostiene que la academia ha sido propensa a "territorializar" el territorio, subordinándolo a ser una parte más, a ser funcional al núcleo de disciplinas mencionadas anteriormente (2005, p. 9). Dicha marginalización del concepto ha producido que no se analicen todas las interconexiones que pueden darse al centrar la atención en el concepto mismo.

3 Territory is not simply about sorting things in space for its own sake but is always a means to some other end - and these ends are by no means restricted to universal needs. Territory may be a solution to a problem. It may be a kind of strategy. Because territory always involves the communication of some sort of meaning and is essentially classificatory, it may have the function (or at least the effect) of reifying forms of identity and difference. It is very often a means of controlling what is "inside" the lines by limiting access or excluding others. As compared with others means of asserting control, territory may promote clarity and simplicity, and therefore certainty and predictability, and therefore peace, security and order, and therefore efficiency and progress (Delaney, 2005, p. 19). 
En este punto es donde aparece un segundo concepto: territorialidad. Esta no se reduce únicamente a entender el territorio desde una estrategia por el control del espacio, sino que es una figura complementaria, ya que la territorialidad

se entiende mejor como implicar y estar implicado en formas de pensar, actuar y estar en el mundo - formas de construir mundo basadas en creencias, deseos y formas de conocimiento cultural e históricamente contingentes. Es tanto un fenómeno metafísico como material. [...] Da forma y está conformado por la conciencia colectiva e individual (Delaney, 2005, p. 12).

En ese orden de ideas, puede entenderse el Macizo como un territorio con múltiples territorialidades en conflicto y en articulación constante. Ahora bien, ¿qué significa entender el Macizo como un territorio hidrosocial? Esto nos lleva, en primera instancia a hablar de la delimitación de este territorio. El estar conformado por distintas territorialidades (estatal, campesina e indígena) que dan al territorio del Macizo distintos significados (como ecorregión, como territorio campesino o como Cabildo indígena), permite establecer relaciones entre significado y poder, como clave explicativa de las relaciones que cada una de estas tres territorialidades establecen con el agua y viceversa. El agua juega un rol central en la delimitación (física, para el caso del Estado y el Cabildo, y de rango de acción, para el caso del CIMA) para los tres casos, pero difiere en los significados, como se muestra a lo largo del trabajo.

Las diferencias frente a lo que es el Macizo para cada uno varían en cuanto a que para el Estado es una zona estratégica con recursos naturales clave para la sostenibilidad de todos los pobladores del país, mientras que, para los indígenas y los campesinos, se construyó una identidad en torno al agua y la tierra que derivó en exigencias por derechos, no solo por servicios públicos, sino por autonomía política dentro del Estado colombiano. 
Este argumento se desarrollará en diálogo con la propuesta metodológica de Boelens et al., a partir de cuatro puntos: 1) relación entre redes hidrosociales y territorialización; 2) las escalas en las cuales operan estas configuraciones territoriales; 3 ) gubernamentalización del territorio; y 4) a modo de conclusión, se propone mostrar cómo estos elementos nos permiten reafirmar que este proceso continúa reconfigurando territorialidades del Macizo, en las cuales el agua continua teniendo un rol central, como objeto de disputa material y discursiva.

\section{¿Cómo definir el Macizo ${ }^{4}$ Colombiano?}

Para poder entender cómo interactúan estas tres territorialidades, partiremos de la definición que el Estado colombiano ha ido construyendo en los últimos 30 años, la cual se resume en el documento CONPES 3915, del 16 de enero de 2018. Allí se establece que el Macizo Colombiano es una “ecorregión” y "una región estratégica para el país. La convergencia orográfica, [... la riqueza ecosistémica y su tipo de suelo generan...] condiciones especiales que favorecen la regulación hídrica y el mantenimiento de una alta riqueza biológica, paisajística y cultural” (CONPES 3915, 2018, p. 12). Igualmente resalta el documento que:

Esta ecorregión se encuentra localizada sobre la cordillera de los Andes en el suroccidente del país y cubre una extensión de 4,8 millones de hectáreas [4,2 \% del área continental de Colombia]. Está conformada por 89 municipios de 7 departamentos, sobre los que tienen jurisdicción 6 Corporaciones Autónomas Regionales y de Desarrollo Sostenible. Su delimitación fue realizada con base en consideraciones de tipo geológico, ambiental, social, histórico y político administrativo. Desde 1978, cuando fue declarada por

4 En orogenia la palabra macizo se utiliza para "referirse a las áreas montañosas cuyo núcleo está constituido de roca ígnea plutónica masiva o metamórficas, parcialmente erosionadas. [...] En casos especiales puede referirse a regiones montañosas de núcleos conformados por rocas sedimentarias, que abarcan áreas extensas” Diccionario Geológico, 3. ${ }^{\mathrm{a}}$ edición, recuperado en: http://www.geoss.com.pe/docs/ DICCIONARIO \%20GEOLOGICO.pdf 
la UNESCO como Reserva de la Biósfera Constelación Cinturón Andino, se ha generado una serie de orientaciones de política para promover su desarrollo con base en su capital natural. Esto, no solo para mantener la capacidad de generar servicios ecosistémicos para el Macizo, sino para aquellos territorios hidrográficamente interconectados que se benefician de este. Lo anterior, debido a que en esta región se originan las cordilleras Central y Oriental, y confluyen los ecosistemas andino, amazónico y pacífico. Además, en el Macizo nacen las cinco arterias fluviales más importantes del país: los ríos Magdalena, Cauca, Putumayo, Caquetá y Patía, razón por la cual se ha denominado a esta ecorregión como la estrella fluvial colombiana (CONPES 3915, 2018, p. 8).

La región, además, cuenta con 362 cuerpos de agua que suponen una reserva hídrica de gran valor para el desarrollo sostenible, mediante la diversificación de actividades productivas como el ecoturismo y la piscicultura (Vásquez y Arias, 2015, p.21; CONPES 3915, 2018, p. 19).

El Macizo [también] alberga siete de los treinta y seis complejos de páramo ${ }^{5}$ existentes en el país, con un área de 779.084 hectáreas que equivalen al 16 \% de la extensión de la ecorregión (Instituto de Investigación de Recursos Biológicos Alexander von Humboldt (IAvH), 2012). A septiembre de 2017, dos de estos complejos cuentan con delimitación (Chili-Barragán y Las Hermosas), mientras que los demás serán delimitados a 2018 (CONPES 3915, 2018, p. 17).

Un segundo aspecto a resaltar es el demográfico, pues el Macizo es caracterizado como un territorio intercultural compuesto por diferentes grupos poblacionales:

5 Los complejos de páramo existentes en la ecorregión son: (i) Las Hermosas (208.011 ha); (ii) Nevado del Huila-Moras (150.538 ha); (iii) Guanacas-Puracé-Coconucos (137.677 ha); (iv) Sotará (80.929 ha); (v) La Cocha-Patascoy (145.539 ha); (vi) Doña Juana-Chimayoy (69.263ha); y (vii) Chili-Barragán (80.708 ha) (CONPES 3915, 2018, p. 18). 
Existe una presencia significativa de comunidades indígenas ${ }^{6}(10 \%)$ y afrodescendientes (7 \%) y un alto porcentaje de población campesina y mestiza (83 \%). Los principales departamentos con presencia de población campesina e indígena son el Valle del Cauca, Cauca, la vertiente occidental de Nariño y los municipios del costado oriental del Huila y Putumayo (CONPES 3915, 2018, p. 21).

Paradójicamente, estos grupos poblacionales poseen tierras muy ricas para la agricultura en ecosistemas muy frágiles, afectados por procesos de colonización y amenazados por la locomotora minera, la cual continúa avanzando como columna vertebral del modelo de desarrollo de Colombia.

En esta definición, el Estado ha buscado incluir otras territorialidades (indígenas y campesinas) existentes a lo largo y ancho de los departamentos que abarca, por lo cual se podría considerar que esta propuesta es un tipo de territorio hidrosocial. Sin embargo, trayendo a colación la propuesta de Boelens et al. (2017), este modelo de ecorregión solo se preocupa por la distribución de servicios ecosistémicos de forma sostenible, lo cual no incluye otros posibles significados y relaciones que establecen los pobladores con el agua.

Dicho lo anterior, vale la pena profundizar en los factores históricos que incidieron en la constitución de esta ecorregión a lo largo del decenio de los años noventa, y cuya mayor transformación produjo una nueva relación entre agua, sociedad y Estado, en la cual el agua se perfila como el eje central de articulación de las políticas públicas, y entre distintos actores, para los siguientes treinta años. Sin embargo no llega

... los resguardos indígenas en el Macizo tienen una extensión de 217.000 hectáreas (DANE, 2005), que corresponden al 4,5 \% del total de la ecorregión, en las que hay presencia de trece grupos étnicos: Yanacona, Páez (o Nasa), Guambiano (o Misak), Coconuco, Inga, Kamsáes (o Camentza), Embera, Pijao, Quillancinga, Awá, Pastos, Cofan y Totoró. Estos grupos étnicos se encuentran distribuidos de manera dispersa en toda la región, aunque con mayor concentración en el departamento del Cauca (CONPES, 2018, p. 21). 
perfilarse el agua como un actor (o actante para ponerlo en términos de Latour $^{7}$ ) con capacidad de incidir en la delimitación de la ecorregión. Aquí encontramos otra diferencia con el modelo de territorios hidrosociales propuesto por Boelens et al., puesto que en este tipo de configuraciones se considera el agua un actor más, decisivo en la configuración del territorio y, particularmente, en la relación entre Estado y sociedad.

El origen de la delimitación del Macizo Colombiano se encuentra asociado temporal y espacialmente a su geografía montañosa y su variedad de fuentes hídricas. Dicha definición, antes de los años noventa, se asociaba con áreas geográficas específicas, como el Nudo de Almaguer, en el que nacen las cordilleras Central y Oriental, y que fue el territorio ocupado en el siglo XVI por buena parte del distrito minero de Almaguer, donde existían dos provincias, Guachiconu y Papallata, habitadas por el pueblo indígena Yanacona. Estas dos provincias han sido reivindicadas por esta comunidad como el corazón del Macizo Colombiano (Zambrano, 1993, p. 25).

A mediados de los años cuarenta del siglo xx, Ernesto Guhl enfatizó lo relativo a la estructura de los Andes, destacando que el Macizo era la unión de las tres cordilleras de la siguiente manera: "hacia el sur existen altiplanos y pequeños valles en dirección E-O, hacia el pacífico, mientras al norte, los grandes valles tectónicos se abren en dirección S-N hacia el Atlántico” (Guhl, citado en López, 2014, p. 26).

Para esta nueva delimitación del Macizo se optó por agrupar municipios que tienen jurisdicción en el cinturón andino (conformado por los Parques Nacionales Naturales de La cueva de los Guácharos, Puracé y el Nevado del Huila), declarado "reserva de la biosfera” por la UNESCO

7 "Actante es un término de la semiótica que cubre a la vez a los humanos y los nohumanos; es un actor todo aquel / aquello que modifica a otro en una prueba". Disponible en: http://www.brunolatourenespanol.org/00_Glosario_actante.htm (consultado el 01/04/2017) 
en 1979. Estas reservas son "ecosistemas terrestres y/o marinos protegidos por los Estados y por la Red Mundial de Biósferas, cuya función principal es la conservación de la biodiversidad del planeta y su utilización sostenible" .

La importancia hídrica y orográfica de la región es la característica que ha primado en la definición del Macizo desde la época colonial. Lo que ha cambiado con el paso del tiempo es el conocimiento sobre esta, y el significado que adquiere para cada actor en tiempos y espacios diferenciados. En la década de los noventa, el discurso conservacionista se enfocó en los páramos, por la capacidad que tienen para retener grandes volúmenes de agua y regular su flujo a través de las cuencas hídricas (Ministerio de Medio Ambiente, 2002, p. 20), amenazadas por factores como la colonización y el conflicto armado ${ }^{9}$, que continúan afectando en la actualidad la gobernanza territorial ${ }^{10}$ del Macizo.

8 Esta definición de Reserva de la Biosfera se encuentra disponible en: http://www. unesco.org.uy/mab/es/areas-de-trabajo/ciencias-naturales/mab/programa-mab/ reservas-de-biosfera.html (consultado el 12/02/2017)

9 En la actualidad la colonización y el conflicto armado continúan teniendo incidencia en el territorio, como se señala en el CONPES 3915:

Su incidencia ha generado cerca de 636.857 víctimas, en su mayoría desplazados internos, y ha afectado cerca de 6.200 hectáreas por el establecimiento de cultivos de uso ilícito. En este sentido, de acuerdo con el Îndice de Incidencia del Conflicto Armado del DNP (2016), 16 municipios de esta ecorregión están catalogados como de alta y muy alta incidencia del conflicto armado (CONPES 3915, 2018, p. 23).

Por eso:

en esta región dieciocho municipios hacen parte de las zonas incluidas en los Programas de Desarrollo con Enfoque Territorial (PDET). Del Alto Patía están los municipios de Piendamó, Caldono, Caloto, Corinto, Mercaderes, Jambaló, Miranda y Toribio del departamento del Cauca y los municipios de Florida y Pradera del departamento del Valle del Cauca; de la cuenca del Caguán se incluyó a Belén de los Andaquíes y San José del Fragua del departamento del Caquetá; del departamento del Putumayo están Mocoa, Orito y Villagarzón; y del sur del Tolima, Chaparral, Planadas y Rioblanco (CONPES 3915, 2018, p. 24-25, el resaltado es mío).

10 "La gobernanza territorial es definida como la manera de gobernar que se propone el desarrollo económico, social e institucional duradero, promoviendo un sano equilibrio entre el Estado, la sociedad civil y el mercado de la economía" (CONPES 3915, 2018, p. 24, n. 20). 
Ahora bien, teniendo en cuenta que son múltiples los actores que intervienen en la construcción de una ecorregión tan extensa como el Macizo, nos centraremos principalmente en mostrar las interrelaciones entre tres actores principales del territorio. En primer lugar, está la institucionalidad ambiental (Parques Nacionales, Ministerio de Medioambiente, IDEAM, entre otros); en segundo y tercer lugar, al Cabildo Mayor Yanacona (CMY) y al Comité de Integración del Macizo Colombiano (CIMA) (Zambrano, 2001; Tocancipá-Falla, 2006). Durante los años noventa, las tensiones entre el Estado y las comunidades campesinas e indígenas aumentaron, debido a la apertura económica que afectó a muchos cultivadores de café en todo el país, pero en el caso del Macizo se sumó además el escalamiento del conflicto armado, especialmente en el sur del Cauca y el norte de Nariño, en donde, paralelamente al proceso de reorganización de la institucionalidad relacionada con el ordenamiento ambiental y territorial que llevó el Estado colombiano, se consolidaron propuestas políticas de territorialidad indígena y campesina, lideradas por el CMY y el CIMA, respectivamente.

Estas tensiones son las que justamente han dado forma a este territorio hidrosocial en el cual se traslapan estas tres territorialidades que, como se verá a continuación, van más allá de la delimitación estatal del Macizo como ecorregión. Sin embargo, un elemento que permite pensar nuevas formas de relación entre Estado y sociedad es justamente el hecho de que esta delimitación estatal prioriza el agua como eje del ordenamiento territorial, a partir de las cuencas de los ríos Putumayo, Patía, Caquetá, Alto Magdalena, Cauca, y recientemente el Saldaña, en el sur del Tolima (CONPES 3915, 2018, p. 15).

\section{Redes hidrosociales y territorialización}

Boelens et al. (2016, p. 4) señalan que las redes hidrosociales están conformadas en torno al agua y sus usos, y que en muchos casos se caracterizan por ser precarias y no necesariamente exitosas en el ordenamiento territorial. Para analizar cómo se constituyen estas redes es 
necesario tener en cuenta tres factores: 1) el alcance o extensión de la red; 2) la durabilidad de la misma, la cual depende de qué tan fuerte y establecida está la asociación entre las partes; y 3) el rol del agua como actante en estas relaciones.

Como ya se mencionó, durante la década de 1990 el Estado le apostó a la ecorregión como figura territorial para organizar el Macizo. Esta se creó con base en el Plan Nacional de Desarrollo 1998-2002, a partir de tres criterios:

(i) su delimitación, de acuerdo con unidades ecológicas prioritarias para la retención y regulación del agua; (ii) la condición de que este territorio sea compartido por varias corporaciones autónomas regionales y entes territoriales, lo que las convierte en elementos articuladores y dinamizadores del trabajo colectivo en torno al ambiente; y (iii) su carácter estratégico, definido por la posibilidad de articular su oferta natural a la solución de los conflictos actuales relacionados en forma inmediata con los principales procesos y objetivos económicos y sociales contemplados en el Plan Nacional de Desarrollo Cambio para Construir la Paz (DNP, 1998, p. 358).

En ese sentido la ecorregión puede ser considerada como un territorio hidrosocial, en cuanto pone en su centro el agua como eje articulador del ordenamiento territorial, donde los páramos, bosques, sabanas y cuencas resultan fundamentales para el sostenimiento de una región, porque cumplen "funciones de soporte vital para la sociedad a través de la prestación de bienes y servicios ecológicos fundamentales" como el abastecimiento de agua, la generación de energía o el mantenimiento de climas y suelos para la producción de alimentos (Márquez, 2003, p.2). Sin embargo, la definición de territorio hidrosocial es mucho más amplia que la de ecorregión, pues no se restringe al ámbito de los servicios ecosistémicos exclusivamente, sino que busca dar cuenta de las relaciones más complejas entre agua, sociedad y Estado.

Teniendo clara esta diferencia, la conformación del Macizo como ecorregión se viene gestando desde la suscripción del "Convenio 
Intercorporativo para el Macizo Colombiano” en 1995, el cual se basó en una alianza interinstitucional entre el Ministerio de Medio Ambiente, Parques Nacionales Naturales de Colombia (PNNC) y las Corporaciones Autónomas Regionales (CAR) que tenían jurisdicción en ese momento en la región. Luego, para 1998, el IDEAM y Cormagdalena entraron a formar parte del Convenio, con lo cual el primero realizó un estudio que resaltó el Macizo, no solo por la riqueza de sus recursos naturales, sino por la "riqueza histórica, étnica y cultūral, amenazada por la magnitud e intensidad de los fenómenos de ocupación y utilización de los sistemas naturales del Macizo, los cuales son altamente frágiles” (IDEAM, 1999, p. 2).

Este estudio hizo una lectura completa del Macizo, caracterizándolo y explicando los factores que afectan y degradan su entorno, entre los que se destacan las actividades agropecuarias, los cultivos de uso ilícito y la alta densidad demográfica, que presionan la capacidad de amortiguamiento de estos ecosistemas. Son particularmente importantes los ecosistemas de Alta Montaña: allí se identificaron

17 focos de colonización. [...] Parte de las tierras taladas se dedican al establecimiento de cultivos ilícitos, con aproximadamente 18.000 ha de amapola para 1995. Su erradicación ha provocado la ampliación de la frontera agrícola hacia zonas más altas y de difícil acceso dentro de estos ecosistemas (IDEAM, 1999, p. 4).

Posteriormente, en el año 2000, Parques Nacionales, con su programa de conservación "Parques con la Gente”, implementó la estrategia de sistemas agrarios sostenibles con la cual buscó construir "modelos alternativos sostenibles de desarrollo local, seguridad alimentaria e ingresos estables para las comunidades que, a su vez, permitían el desarrollo de objetivos de conservación biológica y protección cultural" (UAESPNN, 2001, p. 89). El éxito aparente de la política al parecer radicó en que la institución no llegó prometiendo recursos a las comunidades, porque la asignación presupuestaria fue muy baja para ese momento. Por esa 
razón, el trabajo se concentró en la capacitación y reconocimiento de los valores culturales. En esa línea, un segundo resultado fue reconocer el potencial de las fincas y las tecnologías utilizadas por las mismas comunidades, para entender "las relaciones agroecosistémicas y culturales” en su conjunto, y no concentrándose solo en una actividad productiva (UAESPNN, 2001, p. 93).

Durante estos años, también se construyeron propuestas de territorialidades campesinas e indígenas, que en el sur del Cauca y el norte de Nariño fueron lideradas por el Comité de Integración del Macizo Colombiano, CIMA, y por el pueblo indígena Yanacona, a través del Cabildo Mayor Yanacona, CMY. Sus propuestas territoriales igualmente estaban muy vinculadas al tema ambiental, pero diferían en cuanto al tema identitario. En ambos casos, el agua es considerada un ser viviente y dador de vida; sin embargo, para el pueblo Yanacona existen una variedad de ritos y creencias que sin duda producen una relación diferente con ella de la que se produce desde el campesinado. Ahora bien, en el marco de la conservación promovida por las instituciones ambientales para el Macizo, ambas organizaciones fueron vinculándose a proyectos e iniciativas promovidas desde la institucionalidad y las ONG vinculadas al tema ambiental, lo cual llevó al CIMA a participar en el proyecto de conservación Promacizo (2004-2007), el cual, a su vez, le permitió adquirir herramientas técnicas para el trabajo con sus organizaciones de base, pero también para fortalecer su apuesta política de identidad maciceña y campesina (puesto que la mayoría de personas que la componen la asociación se identifican como tal), la cual retomaré más adelante. En este proyecto, el CIMA tenía que generar encadenamientos productivos agroambientales en 19 municipios ubicados en Nariño y Cauca: para hacerlo, se identificaron algunas cuencas y se formaron algunas personas para la construcción de planes de manejo de las mismas (Promacizo, 2004, p. 111).

En el caso del pueblo Yanacona, su participación en estos proyectos se dio en programas como Familias Guardabosques, algo que para el 
gobierno de turno fue complementario a la identidad de este pueblo indígena, el cual se considera a sí mismo guardián del Macizo. El programa se enfocó en la erradicación de cultivos de uso ilícito mediante el pago en dinero a las familias, que no necesariamente se destinó para invertir en la conservación y que, por el contrario, llegó a crear divisiones dentro del proceso Yanacona, como lo señala Camargo (2010, p. 102).

Más allá de la acción con daño realizada por el Estado a partir de mezclar estrategias de conservación con estrategias de guerra para la "erradicación de cultivos ilícitos”, es llamativo que en este contexto de la conservación movimientos sociales agrupados como el CIMA y el CMY hayan fortalecido sus apuestas políticas y territoriales, desde una apropiación crítica de estos programas (que no siempre fueron exitosos, como ocurrió en el caso del pueblo Yanacona y el programa de Familias Guardabosques), contribuyendo de este modo al fortalecimiento y consolidación de sus territorialidades (campesina e indígena), disputando espacios, pero también complementando a la territorialidad estatal promovida bajo la figura de ecorregiones.

A esta interacción entre varias territorialidades (Boelens et al., 2016) se le conoce como verticalidad y, según Delaney, es una dimensión territorial que permite entender cómo una multiplicidad de territorios aparecen superpuestos en distintos niveles, no reducidos horizontalmente a dos tipos o mosaicos de territorios, exclusivamente delimitados como afuera/ adentro, interno/externo, o domestico/extranjero (Delaney, 2005, p. 31). Tal es el caso del territorio hidrosocial del Macizo, en el cual se da la interacción de tres territorialidades dentro de un mismo espacio, pero con límites diferenciados entre ellos. En este caso, una de estas territorialidades (la ecorregión estatal) es hegemónica sobre las otras, lo cual da cuenta de las asimetrías de poder que existen entre ellas.

Pero, ¿cuál es el rol del agua aquí? Si se mira el mapa 1, por un lado se puede observar la territorialidad del agua, a partir de los ríos y las cordilleras que ayudan a formar las vertientes por donde se mueven 
estos, los cuales a su vez, sirven para delimitar la ecorregión de una manera más bien instrumental, teniendo en cuenta que la extensión de la misma obedece también a intereses económicos y a facilidades administrativas que permitan al Estado una gestión del agua, al igual que de otros recursos, de manera más homogénea.

La delimitación de los municipios también está mediada por los cauces de los ríos y quebradas que delimitan internamente al Macizo, dando forma a la territorialidad estatal (que no obedece únicamente a criterios técnicos). Finalmente, encontramos las territorialidades campesina (CIMA) e indígena (CMY), ubicadas en veredas o zonas delimitadas administrativamente por el Estado, pero apropiadas por estos procesos organizativos de base. Estas áreas se encuentran ubicadas dentro de la zona nuclear del Macizo (delineada en el mapa 1 en color anaranjado), correspondiente a los municipios del sur del Cauca y el norte de Nariño.

Volviendo a los tres aspectos resaltados al inicio de este acápite, se puede decir que, por lo menos hasta el año 2006, la transformación de la institucionalidad ambiental facilitó la extensión y creación de redes territoriales en defensa del agua y la conservación de los ecosistemas de la ecorregión del Macizo. No se puede decir que haya logrado incidir en el ordenamiento territorial como tal, pero sí ha cumplido un rol en términos de formación ambiental para las comunidades, y de avances en el conocimiento del Macizo por medio de expediciones científicas. La Segunda Expedición Técnica y Científica al Macizo Colombiano, realizada en 2015, buscó incidir en la promulgación del documento CONPES para el Macizo Colombiano, con el que se pretendía una "mejor articulación para la gestión ambiental de la ecorregión” (Macías et al., 2015, p. 62). En esta expedición participaron casi las mismas instituciones que habían apoyado la primera expedición en 1993, como son la Gobernación del Huila, la Federación Nacional de Cafeteros y Cormagdalena, y otras instituciones ambientales.

Sin embargo, es llamativo que los movimientos campesinos e indígenas que habitan en el sur del Cauca y el norte de Nariño hablan poco de 
estas expediciones. Aunque ha participado en estas, el Cabildo Yanacona no necesariamente las reconoce como un espacio de conocimiento y reconocimiento del territorio, pues su relación con este se da por otras vías, que están más en consonancia con su plan de vida (Zambrano, 1993). De igual manera ocurre con el cima pues, para este movimiento, su relación con el agua, y por ende con las redes que dan forma al proceso de conformación del Comité, es explicada apelando a la metáfora del crecimiento de un río, "un río grande donde caímos todos los arroyitos del Macizo” (CNMH, 2018, p. 11).

Es decir que la relación entre estas redes (políticas, de conocimientos, etc.) va dando forma al territorio hidrosocial, en el que confluyen distintas visiones y relaciones en torno al agua del Macizo, no necesariamente complementarias, pero que tienen en común apuestas por la defensa de la misma.

\section{Escalas y reconfiguración territorial}

La reconfiguración territorial del Macizo ocurre en varias escalas, y para entender este proceso es necesario partir de la delimitación hecha por el IDEAM en 1999. En este análisis, técnico y muy detallado, se justificó la expansión del Macizo y su ordenamiento en dos grandes zonas: una nuclear y otra de influencia (Mapa 1). En ese momento se contemplaron 65 municipios (IDEAM, 1999, p. 181-182), y todavía no se incluía al departamento del Valle del Cauca. Luego, con la implementación de proyectos esta zona se amplió, y en la actualidad incluye 89 municipios, de los cuales por lo menos 33 conforman la zona nuclear, ubicados entre los departamentos del Huila, Cauca, Putumayo y Nariño ${ }^{11}$. En esta zona

11 En el Cauca: La Sierra, Popayán, La Vega, Sucre, Timbío, Sotará (Paispamba), Bolívar, Almaguer, San Sebastián, Santa Rosa, Puracé (Coconuco), Rosas; en Huila: La Plata, La Argentina, Saladoblanco, Isnos, San Agustín, Oporapa, Pitalito, Palestina; en Nariño: San Pablo, La Unión, San Lorenzo, Colón (Génova), La Cruz, Belén, San Pedro de Cartago, San Bernardo, Arboleda, Albán (San José), Tablón de Gómez; y en Putumayo: Mocoa y San Francisco (IDEAM, 2002, p. 28-32). 
se encuentran los nacimientos de los ríos Cauca, Caquetá, Magdalena, Putumayo y Patía. Estos municipios nucleares son aquellos en donde el CMY y el CIMA desarrollaron y consolidaron sus proyectos políticos y sus apuestas territoriales, las cuales en la actualidad no se reducen únicamente al Macizo, pues ambas organizaciones se han proyectado políticamente a escala nacional, especialmente el CIMA, que tiene una gran influencia dentro del Coordinador Nacional Agrario (CNA), cuya gran apuesta es la construcción de territorios agroalimentarios interétnicos. Para el caso del Macizo, el primero de estos fue proclamado en noviembre de 2016 en el municipio de San Pablo, Nariño, como Territorio Campesino Agroalimentario del $\mathrm{Macizo}^{12}$.

De esta manera va tomando forma el territorio hidrosocial del Macizo, compuesto por diferentes territorialidades relacionadas con el agua y por unas relaciones de poder diferenciadas, en las que sobresale la delimitación hecha por la institucionalidad ambiental, por encima de la propuesta hecha por el CIMA. La primera se basa en categorías que facilitan el manejo del recurso hídrico, entendiéndolo como una red jerarquizada, poniendo en primer nivel a los grandes ríos; en segundo nivel, a sus afluentes directos; en tercero, a los cuerpos de agua tributarios de los afluentes; y en cuarto nivel, los que vierten sus aguas a estos últimos (IDEAM, 1999, p. 30).

Frente a esto, es importante señalar el papel que cumplen los grandes ríos (ver mapa 1), Magdalena, Cauca, Caquetá, Patía y Putumayo, porque se convierten en frontera del territorio hidrosocial y, en el caso del Magdalena y el Cauca, también tienen un segundo rol, puesto que son epicentro de las economías y sustento de las poblaciones que atraviesan dentro y fuera de esta ecorregión. Igualmente ocurre con los ríos más pequeños y las quebradas que definen límites entre municipios.

12 Un interesante artículo del profesor Carlos Duarte sobre este tema se puede consultar en: http://lasillavacia.com/silla-llena/red-rural/historia/los-territorios-campesinos-agroalimentarios-59671 (consultado el 06/03/2017) 
Esta relación con el agua se evidencia también en el eslogan de la Segunda Expedición al Macizo, “tierra de agua” (Macías, A. et al. (2015) el cual da cuenta de una mayor interdependencia entre agua, sociedad y Estado. Ahora bien, si establecemos una relación entre poder y significado, se podría considerar al agua un actante (en términos latourianos), no solo porque el Macizo sea una fábrica de este precioso recurso, sino porque también entra a jugar en las disputas por el significado de las territorialidades del CIMA y del CMY. Más allá de los aspectos físicos del agua, ¿qué tan determinante resulta a la hora de definir territorialidades campesinas o indígenas?

Para el caso del pueblo Yanacona se evidencian disputas con la delimitación estatal, que no solo se traducen en términos del uso y acceso a la tierra y al agua, sino de significados simbólicos expresados por medio de sus prácticas culturales. Por ejemplo, las lagunas del Macizo (como La Magdalena) son símbolos sagrados, creadores de vida, y por esa razón, desde su cosmología, no deben beber agua directamente de estas, las cuales, irónicamente, son lugar de nacimiento de los grandes ríos, de los cuales depende al menos el 70 \% de la población del país. Esto tampoco ha evitado que en ocasiones acudan a estos sitios sagrados a pescar y a extraer oro de aluvión. La extracción de agua para consumo se hace a través de acueductos construidos en puntos específicos, que llaman “ojos de agua” (Anacona, 2000, p. 115). Las lagunas también son vistas como antepasados, con forma humana. El mito de origen de la laguna La Magdalena da cuenta de ello, pues lleva ese nombre por una mujer llamada Magdalena que iba a ser bautizada por los españoles. Cuando estos "la iban a alcanzar, se volvió laguna, era una india y se volvió agua, y se quedó allí, laguna la Magdalena” (entrevista a comunero realizada por Nantes Cruz, 2000, p. 117). Las lagunas, como sitio de origen de la vida, también se relacionan con plantas utilizadas en su dieta, como el plátano, el café, el maíz, la caña de azúcar y la papa.

En cuanto a los páramos, su principal característica es la capacidad de absorber grandes cantidades de agua y distribuirla a los distintos 
tributarios (ríos, lagunas y quebradas) de los cinco grandes ríos (Patía, Putumayo, Magdalena, Cauca y Caquetá). Este tipo de ecosistema se encuentra en rangos altitudinales superiores a los $3000 \mathrm{msnm}$,

su valor primordial se basa en la regulación hidroclimática, en cuanto es fuente y retenedor de agua. Presenta una vegetación característica como los frailejones, pajonales y chuscales, con una gran variedad de especies endémicas de fauna y flora y su valor ecológico es fundamental (IDEAM, 1999, p. 166-167).

Para los Yanacona, los páramos son considerados fuentes de energía espiritual y lugares en donde el tewa (médico tradicional) puede conseguir elementos para sus rituales (Anacona, 2000, p. 115).

Las escalas son producto de "fricciones entre práctica social, procesos relacionados con el ambiente y fuerzas estructurales” (Boelens et al., 2016, p. 5), lo cual implica no solo la reconfiguración del territorio, sino que afecta la correlación de fuerzas, y por esa vía la representación política. Con base en esto, se pueden retomar varios puntos de la experiencia del CIMA y sobre cómo esta incidió en el proceso de reconfiguración territorial del Macizo como territorio hidrosocial. Lo primero que hay que resaltar es que uno de los pilares del CIMA es el tema ambiental, que se sintetiza en el Plan de Desarrollo Agropecuario y Ambiental del Macizo Colombiano, Pladamasur, de 1999. Su apuesta política para la construcción de región, y la búsqueda de un desarrollo alternativo, contiene ejes que van desde el cuidado del medio ambiente hasta la soberanía alimentaria (Corredor, 2014, p. 101).

La relación del CIMA con el agua se puede entender, en primer lugar, desde la promoción de la producción agroecológica, pues el cuidado del agua es un aspecto central para la producción limpia. Para ello cuentan con redes de agrosembradoras y agrosembradores en los municipios del sur del Cauca y el norte de Nariño, quienes realizan acciones para recuperar microcuencas en las veredas y jornadas de recolección de 
basuras, entre otras actividades. Gracias a esta estructura organizativa en Cauca y Nariño, y a la metodología de campesino a campesino, se han promovido visiones sobre el territorio y la "maciceñidad" (Corredor, 2014), con el objetivo de incidir en distintos escenarios locales, como son los acueductos comunitarios, y discutir políticas de ordenamiento como los planes de ordenamiento territorial y de cuencas.

Sin embargo, más allá de las acciones puntuales y dispersas que cada una de los y las agrosembradoras (pues la mayoría son mujeres) pueda realizar en sus comunidades, no existe un plan concreto de acción frente al tema del agua desde la organización. Por esta razón, una segunda forma de relación que se está promoviendo desde el movimiento campesino, en la actualidad, es incidir en escenarios regionales y locales por medio del Territorio Campesino Agroalimentario del sur del Cauca y norte de Nariño (TECAM), proclamado en 2016, formado por quince municipios con los que se busca construir un Gobierno Campesino autónomo, capaz de decidir sobre el ordenamiento territorial de manera más decisiva. Su constitución se da en un momento en el que la minería amenaza al territorio y las mismas autoridades ambientales regionales son incapaces de poner freno.

Este se constituye en un espacio de confluencia, en el cual participan también organizaciones de base y pobladores que no hacen parte del proceso CIMA, y una de sus proyecciones es construir un plan de vida digna, en el cual la protección, el uso y el acceso a los recursos hídricos tendrán mayor presencia como ejes articuladores de los procesos organizativos territoriales de los municipios que lo componen.

De esta forma, el movimiento campesino reivindica el derecho al agua como mecanismo contra la creciente expansión de proyectos mineros, los cuales son uno de los factores que más está afectando y transformando las relaciones entre agua, sociedad y Estado en el Macizo, amenazando todo el potencial hídrico que en los últimos veinte años el propio Estado ha procurado cuidar junto con las comunidades. 
En la actualidad, la actividad minera aurífera (legal e ilegal) está deteriorando los servicios ecosistémicos de este territorio hidrosocial: a pesar de los altos rendimientos económicos que pueda generar para el país, estos no se ven reinvertidos ni en las poblaciones ni en los la mitigación de los daños ambientales que producen. En el Macizo, dicha actividad se realiza en las seis zonas hidrográficas,

con predominio de algunos municipios del Cauca, y alcanza una producción de 1,4 toneladas al año (en 2016). Los departamentos de Nariño y Cauca aportan el $15 \%$ y el 6,1 \% de la producción a nivel nacional. Los municipios de Nariño con mayor participación en la producción de oro en 2016 fueron Colón y San Pablo, mientras que en Cauca se destacaron Bolívar y La Vega. Además, estos departamentos también son parte de aquellos que presentaron mayor consumo de mercurio en la minería aurea del país [...], con un consumo de 5 y 16,8 toneladas de mercurio anual respectivamente (CONPES 3915, 2018, p. 43).

La situación compleja actual de las formas de territorialidad que confluyen en este territorio hidrosocial, y particularmente las contradicciones que generan estas redes de poder mediante las cuales la hegemonía del Estado se ejerce a través de la ecorregión, parecen indiscutibles sobre las territorialidades campesinas e indígenas. La reconfiguración del Macizo es producto de estas complejas interacciones, que operan en distintas escalas políticas, desde las decisiones autónomas de los pobladores en algunos municipios que conforman el TECAM hasta las políticas públicas generadas por varias instituciones estatales, que no necesariamente están articuladas para garantizar derechos de los pobladores, como lo es el derecho al agua. Por el contrario, lo que buscan es mitigar daños ambientales producto de actividades agropecuarias y minero-energéticas, legales e ilegales. A pesar de ello, este modelo hegemónico de la ecorregión no está exento de contradicciones internas, no solo con sectores de la sociedad civil sino también al interior del propio Estado. 
Un dato indicativo de esta situación queda retratado en el Plan de Acción 2018-2030, para financiar acciones de conservación y desarrollo sostenible, bajo el liderazgo del SIRAP Macizo (Sistema Regional de Áreas Protegidas, adscrito a Parques Naturales). En dicho Plan, el porcentaje de financiación por parte del Ministerio de Minas y Energía y la Agencia Nacional Minera es el más bajo de todas las instituciones implicadas, con tan solo 518 millones de pesos, mientras que otras instituciones, como el Ministerio de Agricultura o la Agencia de Desarrollo Rural, han designado 2.700 y 3.500 millones, respectivamente (CONPES 3915, 2018, p. 82).

Así, estas redes hidrosociales no funcionan de manera homogénea y clara, sino que producen espacios cargados de contradicciones, como es el caso del territorio hidrosocial del Macizo. Por esta razón, el agua es un actor que podría transformar las relaciones entre Estado y organizaciones campesinas e indígenas en el futuro, pero no bajo el modelo estatal de la ecorregión, que continúa en función de generar más opciones para la economía de mercado que para los pobladores de la región. Para comprender estos flujos de poder es necesario preguntarse por la posibilidad de viabilizar formas de gobernanza del territorio, como se analizará a continuación.

\section{Gubernamentalización del territorio}

Mejorar la planificación territorial y la descentralización fue una prioridad para la institucionalidad ambiental durante la década de los noventa. Para ello se establecieron ecorregiones estratégicas, que pudieran ser planificadas en función de la conservación y del desarrollo sostenible, y que a su vez abrieran espacios para la participación más activa de las personas en la protección de los recursos naturales del Macizo. Para Carlos Corredor, por el contrario, la redefinición geográfica surgió de:

una serie de presiones para encontrar conexiones que nunca antes se habían establecido entre diferentes ecosistemas, si bien existieron argumentos 
científicos para esta clasificación y la consecuente redefinición geográfica, fueron en realidad respuestas a intereses políticos regionales que presionaron por su inclusión con el fin de tener acceso a recursos (Corredor, 2014, p. 103).

Aunque lo señalado por Corredor es importante, vale la pena ir más allá de ese hecho para pensar el Macizo como territorio hidrosocial, ya que esto permite pensar en otras articulaciones, más allá de la evidente hegemonía de la propuesta estatal, para mostrar que, a pesar de ser impuesta, esta nueva delimitación también ha servido al CIMA y al CMY para fortalecer sus procesos a partir de interacciones con el agua, que van desde los viejos modelos de recuperación de microcuencas y reforestación hasta nuevos relacionamientos, como son la exigencia del derecho al agua como respuesta a la minería y la recuperación de cosmovisiones relacionadas con este recurso, que trascienden la lógica usufructuaria estatal.

En ese sentido existe complementariedad entre estos tres modos de pensar el territorio y de relacionarse con el agua. Sin embargo, la propuesta de la ecorregión, esbozada en el CONPES 3915, propone como “estrategia para el desarrollo integral del Macizo” la gobernanza multinivel, entendida como:

... la capacidad de la sociedad de resolver sus asuntos y contribuir al desarrollo de sus territorios mediante la articulación y participación de diversos actores territoriales, entre ellos: el Estado, la sociedad civil, las agencias públicas del territorio y el sector privado (2018, p. 70, n. 60).

En este caso, la agencia responsable de facilitar esta articulación es el SIRAP Macizo pues en "los últimos doce años [...] ha logrado articular las autoridades ambientales y algunas entidades territoriales para formular y ejecutar acciones para la protección y el manejo sostenible de los ecosistemas de importancia estratégica de la ecorregión” (CONPES 3915, 2018, p. 71). 
Uno de las metas del SIRAP Macizo es lograr la articulación con las seis gobernaciones (Valle del Cauca, Cauca, Tolima, Huila, Caquetá y Putumayo) de la región para poder hacer más efectivo el cumplimiento y seguimiento de los acuerdos institucionales necesarios que viabilizan las acciones priorizadas en el CONPES 3915 para los próximos quince años. Otra de sus metas es crear redes locales de participación y veedurías ciudadanas en cada una de las seis zonas hidrográficas que componen el Macizo, para que se involucren en la gestión territorial.

De igual manera, deberá incorporar en el plan de acción el mejoramiento y rehabilitación de infraestructura de adecuación de tierras, la evaluación de los efectos del cambio climático en la disponibilidad hídrica, así como la implementación de opciones para enfrentar los riesgos climáticos como inundaciones o sequías, incluyendo aquellas dirigidas a incentivar el uso eficiente del agua por parte de los usuarios (CONPES 3915, 2018, p. 72).

Los componentes de la gobernanza estatal esbozados para la ecorregión del Macizo son útiles para poner en discusión los otros modelos de gobernanza propuestos por organizaciones indígenas y campesinas que habitan allí, y que buscan incidir y participar efectivamente en algunos aspectos del modelo estatal, así como construir un modelo propio para ordenar el territorio, a partir de otro tipo de relaciones que permitan mayor control de las fuentes hídricas disponibles.

Según Boelens et al., los territorios hidrosociales nos deben llevar a pensar en maneras más creativas de romper con la división entre naturaleza y ser humano, a través de redes robustas que permitan transformar los diversos mundos socionaturales que existen en torno al agua, en sistemas de gobernanza dominantes (2016, p. 6). En el caso del Macizo, encontramos ordenamientos construidos a partir de complejas redes entre Estado, sociedad y agua, que nos permiten efectivamente pensar en distintos significados en torno a esta última, la cual, de hecho, potencializa poderosamente las luchas sociales, como ocurre con el CIMA y el TECAM del Macizo, que buscan enfrentar problemáticas como la 
minería o la privatización de los acueductos comunitarios mediante dos estrategias: 1) apropiarse de los mecanismos institucionales que permiten la defensa, protección y gestión comunitaria de este recurso, y 2) llevar a las organizaciones de base que componen el territorio a que transformen su estructura organizativa, de tal manera que se facilite dicha gestión del recurso mediante mecanismos legales establecidos y otros igualmente legítimos, aunque un poco menos regulados e intervenidos por el Estado, como ocurre con los acueductos comunitarios $\mathrm{u}$ otros tipos de estructuras organizativas en torno al manejo de las cuencas en las veredas.

Lo anterior pone en evidencia formas de construcción de hegemonía desde los movimientos sociales (en el sentido más gramsciano del concepto), lo cual no significa que se convierta en un sistema de gobernanza dominante, sino que, por el contrario, está buscando los caminos para llegar a serlo, mediante la interacción con el Estado (y en este caso con la ecorregión), pero no necesariamente bajo las mismas formas jerárquicas y de funcionamiento burocrático que rigen al SIRAP Macizo para operar dentro de la ecorregión. Además, las escalas políticas en las que funciona cada territorialidad son diferentes, y eso se evidencia en las delimitaciones que cada una tiene. Por un lado, una ecorregión estatal con criterios unificados de definición, en contraste con dos territorialidades producidas por reclamos históricos al Estado, ubicadas dentro de la zona nuclear en la que se ubican campesinos e indígenas Yanacona, mayoritariamente al sur del Cauca y el norte de Nariño (ver mapa 1).

Por eso, la constitución del Macizo como ecorregión no deja de ser polémica, pues la ambivalencia de la legislación ambiental frente a temas como la minería genera desconfianza en muchos pobladores, además de que dicha delimitación no tiene necesariamente sentido para los indígenas y campesinos maciceños que habitan allí. Asimismo, los mecanismos de participación propuestos en el CONPES 3915 no dejan mucho espacio para la toma de decisiones desde las comunidades, a pesar que se incluyan procesos de formación que han facilitado el 
diálogo entre el Estado y las comunidades, tan útil desde la década de los noventa, cuando se dio la reorganización de la institucionalidad ambiental.

\section{¿Hacia nuevas formas de ordenamiento territorial del Macizo?}

Recogiendo los puntos presentados anteriormente, en este último acápite se presentan unas conclusiones en clave de reflexión sobre la hidroterritorialidad del Macizo. Uno de los aspectos que resalta de la propuesta de Boelens et al. (2016, p. 7) es el interrogante sobre qué tipo de territorios resultan de la intersección y confrontación de proyectos territoriales divergentes, con lo cual se pone en primer plano el hecho de que las territorialidades que cuestionan la legitimidad del Estado, y logran el reconocimiento de costumbres y el uso de tecnologías propias para manejar sus problemas cotidianos, no solo contribuyen a la estabilidad del sistema sino que abren oportunidades para prolongar las luchas por la defensa del agua, y de este modo generar nuevas relaciones con esta.

Esto nos lleva a pensar otras maneras de entender el poder, y en particular la heterogeneidad del Estado ${ }^{13}$, que para el caso del Macizo se pueden evidenciar en la forma como se delimitó la ecorregión a partir de la necesidad de controlar efectivamente recursos como el agua. Por esa razón, si bien el Estado no es completamente homogéneo (de hecho, su presencia en el territorio se da de manera diferenciada), ante ciertas situaciones y en momentos específicos puede generar respuestas homogéneas, como ocurrió con el conflicto armado durante la década

$13 \mathrm{Al}$ respecto se pueden consultar varios estudios de carácter histórico, que muestran la heterogeneidad del Estado y sus instituciones. En Colombia: González, Fernán (2014) Poder y violencia en Colombia, Bogotá, Cinep/PPP y ODECOFI. De manera más amplia, sobre otro tipo de ordenamientos no estatales, los trabajos de James Scott: Scott, J. (1987) Weapons of the Weak: Everyday Forms of Peasant Resistance, Domination and the Arts of Resistance: Hidden Transcripts, Yale University Press, y Scott, J. (1999) Seeing Like a State. How Certain Schemes to Improve the Human Condition Have Failed, Yale University Press. 
de los noventa, en la zona nuclear del Macizo (sur del Cauca y norte de Nariño). La situación motivó al Estado a controlar esta zona debido a la importancia geoestratégica de la región, pues desde allí se produce el agua para el 70 \% de la población de todo el país. De esta manera, durante esta coyuntura, el tema ambiental fue una estrategia que facilitó dicho proceso y permitió la llegada (fragmentada) de la institucionalidad a zonas rurales que estaban siendo copadas por grupos guerrilleros como las FARC y el ELN. El efecto sobre la población fue diverso: mientras la comunidad indígena Yanacona participó exitosamente en programas de familias guardabosques para dejar los cultivos de uso ilícito, a los colonos se les asoció con actividades ilegales como narcotráfico y pertenencia a las guerrillas, llegando incluso a señalarlos como los responsables de la degradación ambiental del Macizo. Dicha posición aparece en un informe de la Oficina de Derechos Humanos de Vicepresidencia en que se menciona que: "El Macizo Colombiano presenta en la actualidad serios problemas de deterioro en su potencial hídrico y de biodiversidad, debido al acelerado proceso de destrucción, causado por los colonos que arrasan irreversiblemente con bosques y páramos” (Observatorio del Programa Presidencial de Derechos Humanos y Derecho Internacional Humanitario, 2001, p.3). Sin embargo, si se revisa el informe del IDEAM de esa época, se evidencia que el problema radica en que se ubican en zonas poco accesibles, pero muy vulnerables, como lo son efectivamente los páramos y los bosques (IDEAM, 1999, p. 6, 73 y 155).

Pero, ¿de qué manera incidió el conflicto armado en este reordenamiento del Macizo como ecorregión? Para el Estado fue central poder llegar a determinados corredores estratégicos para la movilidad de tropas, como las zonas de alta montaña, para modificar la balanza de poder con los grupos que operaban en la zona. Por eso, no es casualidad que en las zonas donde se implementaron programas de conservación como "guardabosques" se establecieran posteriormente Batallones de Alta Montaña, aduciendo motivos de seguridad, como fue el caso del corregimiento de Valencia, en San Sebastián (Cauca), ubicado en el 
páramo de Las Papas, un delicado ecosistema estratégico de la nación (López, 2014).

Esta forma de actuar sobre el territorio de parte del sector defensa se complementó con la posición de la oficina de Derechos Humanos de la Presidencia mencionada más arriba. De hecho, una actuación similar se puede encontrar en el IDEAM, pues en su estudio "técnico" para delimitar el Macizo aclara que su objetivo no es realizar "el alinderamiento definitivo del área del Macizo Colombiano, pues se acordó el límite político administrativo municipal y las divisorias de cuencas y se tuvo en cuenta, además, zonas de influencia incluidas por razones de soberanía" (1999, p. 5, el resaltado es mío). Aunque no se aclaran cuáles son esas razones de soberanía no es difícil inferir que se relacionan con temas de seguridad.

Lo curioso de este control es que, si bien logró reducir el conflicto en el Macizo, no logró tramitar las demandas de los movimientos sociales de la región. Por su parte, el CIMA y el CMY construyeron propuestas de territorialidad propias (campesinas e indígenas, respectivamente) que por momentos se tornaron altamente confrontativas con las del Estado: ejemplo de ello fueron las grandes marchas del Macizo de los años 1993, 1996 y 1999. Esta coyuntura sirvió para que estos movimientos pasaran de las demandas por servicios públicos de los años 80 (Zambrano, 1993; Nantes Cruz, 2000; Herrera, 2003; García, 2009; Espinosa, 2013), a construir propuestas de ordenamiento territorial como una base sobre la cual se buscan materializar los derechos al territorio (y no solo a la tierra). En el caso del cimA se trata de una propuesta política que busca el reconocimiento del campesino como sujeto de derechos, y para ello han utilizado diversas estrategias, que implican aspectos culturales para rescatar la cultura campesina (maciceña) entre los jóvenes, con actividades artísticas y deportivas, gestionando proyectos productivos y promoviendo educación ambiental y formación política de líderes, llegando incluso a ganar alcaldías en municipios del sur Cauca. La construcción del territorio se ha dinamizado desde la entrada de la 
minería, y en la actualidad su propuesta se sintetiza en la promoción y construcción de Territorios Campesinos Agroalimentarios (CNA, 2014).

En el caso del pueblo Yanacona, se puede decir que el principal logro fue la constitución del CMY en 1993, porque desde allí han consolidado y recuperado la principal área geográfica de su territorio ancestral. La recuperación de su cultura y la delimitación del Cabildo son, entre otros aspectos, son su principal logro (Nantes Cruz, 2000; Zambrano, 1993).

Ambas territorialidades, ubicadas en la zona nuclear del Macizo, apenas han podido mantener la actividad minera fuera del territorio, y por esa razón es fundamental construir redes hidrosociales, y potencializar las ya existentes, para que como movimientos contribuyan a fortalecer a las comunidades locales en cuanto al acceso (y no solo el uso) del agua. Este discurso está siendo incluido por el CIMA en las prácticas desde la cotidianidad, únicamente bajo la forma del derecho al agua, pero poco se ha explorado el potencial político que tienen estas redes construidas desde experiencias locales relacionadas con el agua. En cuanto a las escalas políticas de su actuación, también es importante que busquen nuevas formas de relación con actores clave en el territorio, como son las CAR y la Asociación de Municipios del Macizo Colombiano, Asomac, pues de no hacerlo podrían llegar incluso a reducir su incidencia en los municipios donde se han constituido como proceso. Esto en particular para el CIMA, que tiene una incidencia mayor que el CMY dentro del departamento del Cauca.

Ahora bien, el ordenar el Macizo como ecorregión no solo incumbe a la autoridades ambientales, sino que progresivamente ha permeado a la institucionalidad municipal por medio de asociaciones subregionales, que a su vez son apuestas para la descentralización del ordenamiento territorial promovido desde el Departamento Nacional de Planeación. En este sentido, Asomac y el Plan Patía hacen parte de estas apuestas, mientras que Plademasur fue el plan de desarrollo construido en el marco del Convenio Intercorporativo con las comunidades, y reivindicado 
como eje articulador del CIMA en la región. Esto, para Zambrano, hace del Movimiento del Macizo Colombiano (MMC, que va más allá del CIMA y del CMY) un movimiento moderno, que maneja un leguaje progresista sobre los derechos y redefine el significado de la ciudadanía (Zambrano, 2001, p. 281).

En cuanto a la escala nacional, es importante resaltar de nuevo la apuesta de los Territorios Agroalimentarios impulsados por el CIMA y otras organizaciones municipales del Macizo. Esta propuesta, similar a las Zonas de Reserva Campesina o a los Cabildos Indígenas, surgió en el marco de la plataforma de articulación con otros movimientos regionales agrupados en el CNA (2014).

Por otra parte, la memoria y la historia de las luchas en el Macizo deben ser leídas en este nuevo contexto de confrontación con la minería, de cara a la posibilidad de construir apuestas políticas mucho más vinculadas hacia la interacción con el agua. No hay que olvidar que, para el CIMA, la "pelea por reivindicaciones sociales y también espacios políticos en la región” es central en su funcionamiento, pues en su actuar "es como un rio alimentado de pequeñas quebraditas a donde llegan las veredas, los corregimientos y los municipios..." (comunero del CIMA, citado en Nantes Cruz, 2000, p. 58). Esta asociación del CIMA con un río es un ejemplo de cómo la cultura ofrece múltiples maneras de relacionarse con la naturaleza y cómo la historia misma de la organización aporta elementos que pueden articularse en una relación más orgánica con el agua, en función de las luchas sociales por el territorio.

Ahora bien, aunque el CIMA y el CMY han trabajado mancomunadamente en muchos momentos, es necesario tener en cuenta que el tema de la identidad es un escenario de conflicto, en cuanto se materializa en la expansión de los resguardos y las decisiones que el CMY toma sobre el territorio, pues esto afecta intereses tanto de grandes propietarios como de campesinos y sectores políticos del CiMA (Zambrano, 1993, p. 80). Sin embargo, la protección del agua también puede convertirse en un 
eje que permita articular nuevas relaciones entre estos actores, lo cual no parece fácil de lograr en el corto plazo, especialmente con una Constitución que se ha convertido en la principal herramienta de división entre indígenas y campesinos.

En relación al territorio, entendiendo al Macizo como territorio hidrosocial, lo que se puede concluir parcialmente es que estas interrelaciones entre territorios muestran, de manera muy esquemática, dos elementos centrales para la geografía humana, que Delaney resalta como la relación entre poder y significado. En relación con el primero, se mostró que la ecorregión constituye una figura jurídica que le ha permitido al Estado ejercer su soberanía, poniendo el aspecto militar-estratégico en diálogo con el ambiental para, de esta manera, por medio de Parques Nacionales Naturales acercarse de otra forma a la población y ejercer control sobre ella por esta vía.

Teniendo en cuenta estas asimetrías de poder, la impresión que puede quedar es que la ecorregión puede contener las territorialidades campesina e indígena por el hecho de que se encuentran dentro de su jurisdicción. Sin embargo, estas territorialidades ejercen también un poder propio, pero a niveles más locales y regionales. El caso del CIMA resulta llamativo, pues no solo han logrado movilizar muchos sectores, no solo campesinos, dentro de la zona nuclear (sur del Cauca y norte de Nariño), sino en la zona de influencia del Macizo, convirtiendo la carretera Panamericana en un espacio para esta confrontación-movilización-negociación con el Estado colombiano.

El caso del pueblo Yanacona se destaca por la constitución del Cabildo, reorganizando un territorio mucho más pequeño que el del cimA (municipios de San Sebastián y Sotará) y garantizando su autonomía dentro de él. El territorio indígena está claramente delimitado, al igual que la ecorregión, mientras que el del CIMA lo es mucho menos, ya que se basa principalmente en una red de procesos veredales muy variados de por lo menos veinticinco municipios. 
El proceso de delimitación del Macizo produjo resultados importantes, en cuanto a transformar las relaciones con el agua desde distintas escalas que trascendieron las luchas regionales del CIMA y el CMY. Por otra parte, los avances de estas son todavía muy disimiles, si se comparan con las luchas campesinas e indígenas por el agua en los Andes peruanos y ecuatorianos, en cuanto a las redes, escalas y lugares donde se desarrollaron y construyeron hidroterritorialidades mucho más complejas (Hoogesteger y Verzijl, 2015). En el Macizo, los procesos más fuertes se desarrollan a nivel municipal y de manera fragmentaria. Dicha fragmentación también se evidencia en la territorialidad estatal de la ecorregión, puesto que su éxito a largo plazo depende de una mejor articulación interinstitucional con las gobernaciones. Aun así, se debe profundizar en particular en el entendimiento de la diversidad de interrelaciones con el agua en el proceso de conformación del Macizo, para mostrar otras interacciones entre el Estado y los movimientos sociales que no se lograron explorar a profundidad en este ensayo.

\section{Referencias}

Anacona, Lenin (2000). La cosmovisión Yanakuna: siguiendo el camino andino. http://nacionyanakuna.com/Paginas/Cosmovision/Cosmovision \% 20Yanakuna.htm

Boelens, Rutgerd; Hoogesterger, Jaime; Swyngedouw, Erik; Vos, Jeroen y Wester, Philippus (2016). Hydrosocial territories: a political ecology perspective. Water International, 41(1), 2-14.

Camargo, Sofía (2010). Consecuencias del Plan Colombia. El caso del agua en la Comunidad Yanacona. Quito: Ediciones Abya Yala-Flacso.

Centro Nacional de Memoria Histórica, CNMH (2018). Crecer como un río, vol. 2. Bogotá.

CONPES 3915 (2018, 16 de enero) Lineamientos de Política y Estrategias para el Desarrollo Regional Sostenible del Macizo Colombiano (Documento). Bogotá: DNP. 
Coordinador Nacional Agrario, CNA (2014). Cartilla Territorios Agroalimentarios. Recuperado de: https://cnagrario.files.wordpress.com/2014/11/territorios_agroalimentarios_cartilla_175x250_print.pdf

Corredor, Carlos (2014). Identidad Maciceña, Territorio y Vida Digna: El "lugar" del Comité de Integración del Macizo Colombiano CIMA [Tesis de Doctorado]. Popayán: Universidad del Cauca.

Delaney, David (2005). Territory: a short introduction. London: Blackwell Publishing.

Dirección Nacional de Planeación, DNP (1998). Desarrollo y paz: instrumentos y prioridades para la construcción de la paz. Recuperado de: https://colaboracion.dnp.gov.co/CDT/PND/Pastrana2_Desarrollo_\%20Paz.pdf

(2003). Iniciativas regionales y subregionales de organización territorial: algunos procesos, esquemas, asociaciones y programas que aportan al estudio de la regionalización en Colombia. Bogotá.

Duarte, Carlos (2017). Los Territorios Campesinos Agroalimentarios. La silla vacía. Recuperado de: http://lasillavacia.com/silla-llena/red-rural/historia/los-territorios-campesinos-agroalimentarios-59671 (consultado el 06/03/2017)

Espinosa, Natalia (2013). Acción política campesina en el sur del Cauca. Historia de los campesinos del Macizo Colombiano 1980-1991 [Tesis de Pregrado]. Bogotá: Pontifica Universidad Javeriana.

Fundecima (1999). Plan de desarrollo educativo y cultural del Macizo Colombiano. Popayán: CIMA.

(2000). Maciceña. Revista del Movimiento de Integración del Macizo Colombiano, año 1, núm. 1.

García, Martha Cecilia (2009). Cara y sello: Movimiento Los Inconformes y Movimiento Cívico Popular por Nariño. En M. Archila et al. La Izquierda inconclusa. Bogotá: CINEP/PPP.

Herrera, Luz Ángela (2003). Región, desarrollo y acción colectiva. Movimiento de Integración del Macizo Colombiano. Bogotá: CINEP.

Hoogesteger van Dijk, Jaime y Verzijil, Andres (2015). Grassroots scalar politics: Insights from peasant water struggles in the Ecuadorian and Peruvian Andes. Geoforum, 62, 13-23. 
Instituto de Hidrología, Meteorología y Estudios Ambientales, IDEAM (1999). El Macizo Colombiano y su área de influencia, Módulo Hídrico. Bogotá: Ministerio del Medio Ambiente. (2002). Propuesta de delimitación del área del Macizo Colombiano. Bogotá: Ministerio del Medio Ambiente.

Ley General Ambiental de Colombia (1993). Diario Oficial No. 41.146, de 22 de diciembre de 1993.

López, Yuli (2014). Discursos verdes en el Macizo Colombiano. Tierras y Conflictos socio-ambientales en el Páramo de las Papas [Tesis de pregrado]. Popayán: Universidad del Cauca.

Márquez, Germán (2003). Ecosistemas Estratégicos de Colombia. Sociedad Geográfica de Colombia. Recuperado de: http://www.sogeocol.edu.co/ documentos/07ecos.pdf

Ministerio del Medio Ambiente (2002). Páramos. Programa para el Manejo Sostenible y Restauración de Ecosistemas de la Alta Montaña colombiana. Bogotá: Imprenta Nacional.

Nantes Cruz, Beatriz (2000). De lo Bravo a lo Manso. Territorio y Sociedad en los Andes. Macizo Colombiano. Quito-Manizales: Abya Yala y Corporación Ambiental Madremonte.

Observatorio del Programa Presidencial de Derechos Humanos y Derecho Internacional Humanitario (2001). Panorama Actual del Macizo Colombiano. Bogotá: Vicepresidencia de la República.

PROMACIZO (2004). Programa de conservación y rehabilitación ambiental en el marco del desarrollo sostenible concertado con los procesos socioambientales del Macizo Colombiano. Popayán: Editorial López.

Rodríguez Sánchez, Antonio (2017). Configuración hidrosocial: ipaisaje, territorio o espacio? Waterlat Gobacit Network, Working Papers. Thematic Area Series - TA6, 4(3), 27-41.

Tocancipá-Falla, Jairo (2006). Movimientos Sociales, cultura política y poder regional. El caso del Movimiento del Macizo Colombiano (MMC). Popayán: Universidad del Cauca. 
Unidad Administrativa Especial del Sistema de Parques Nacionales Naturales, UAESPNn (2001). Parques con la Gente. Bogotá: Ministerio de Medio Ambiente.

Vásquez, Adriana y Arias, Eduardo (2015). Macizo Colombiano: tierra del agua. Bogotá: Memorias Segunda Expedición Técnica y Científica al Macizo Colombiano (19-26 de marzo, 2015).

Zambrano, Carlos (Ed.) (1993). Hombres de Páramo y Montaña. Los Yanaconas del Macizo Colombiano. Bogotá: Instituto Colombiano de Antropología y Presidencia de la República de Colombia.

Zambrano, Carlos (2001). Conflictos por la hegemonía regional. Un análisis del movimiento social y étnico del Macizo Colombiano. En M. Archila y Pardo, M. (eds.). (2001). Movimientos sociales, Estado y Democracia en Colombia. Bogotá: Instituto Colombiano de Antropología e Historia y Universidad Nacional de Colombia.

\section{Siglas}

ACIN: Asociación de Cabildos Indígenas

AICO: Autoridad Indígena de Colombia

Asomac: Asociación de municipios del Macizo Colombiano

Asopatía: Asociación de Municipios del Patía

Biomacizo: Proyecto de Conservación de Biodiversidad del Macizo

CAM: Corporación Autónoma del Alto Magdalena

CAR: Corporación Autónoma Regional

CIMC: Convenio Intercorporativo del Macizo Colombiano

CIMA: Comité de Integración del Macizo Colombiano

CIS: Centros Integrados de Servicios Maciceños

CMY: Cabildo Mayor Yanacona 
CNA: Coordinador Nacional Agrario

CNMH: Centro Nacional de Memoria Histórica

Cortolima: Corporación Autónoma Regional del Tolima

Corponariño: Corporación Autónoma Regional de Nariño

CRC: Corporación Autónoma Regional del Cauca

CRIC: Consejo Regional Indígena del Cauca

CVC: Corporación Autónoma Regional del Valle del Cauca

DNP: Dirección Nacional de Planeación

EE: Ecosistemas Estratégicos

FAO: Organización de las Naciones Unidas para la Agricultura y la Alimentación

Fundecima (CIMA-Cauca): Fundación Estrella Orográfica del Macizo Colombiano

Fundesuma (CIMA-Nariño): Fundación del Suroccidente y Macizo Colombiano

IDEAM: Instituto de Hidrología, Meteorología y Estudios Ambientales IGAC: Instituto Geográfico Agustín Codazzi

Inderena: Instituto Nacional de Recursos Naturales Renovables y del Ambiente

MMA: Ministerio del Ambiente

MMC: Movimiento del Macizo Colombiano

Pladamasur: Plan de Desarrollo Agropecuario y Ambiental del Macizo Colombiano 
Plademaco: Plan de Desarrollo educativo del Macizo Colombiano y sur del Cauca

PNNC: Parques Nacionales Naturales de Colombia

Promacizo: Programa de Conservación y Rehabilitación Ambiental del Macizo Colombiano

PSA: Pago por servicios ambientales

Sina: Sistema Nacional Ambiental

Sinap: Sistema Nacional de Áreas Protegidas

SIRAP Macizo: Sistema Regional de Áreas Protegidas del Macizo Colombiano

TCA/TECAM: Territorios Campesinos Agroalimentarios. También es utilizada para referirse al Territorio Campesino Agroalimentario del Macizo (del norte de Nariño y sur del Cauca)

UAESPNN: Unidad Administrativa Especial del Sistema de Parques Nacionales Naturales

Unesco: Organización de las Naciones Unidas para la Educación, la Ciencia y la Cultura

WWF: Fondo Mundial de Protección de Vida Silvestre

ZRC: Zonas de Reserva Campesina 


\section{ECORREGIÓN DEL MACIZO COLOMBIANO}

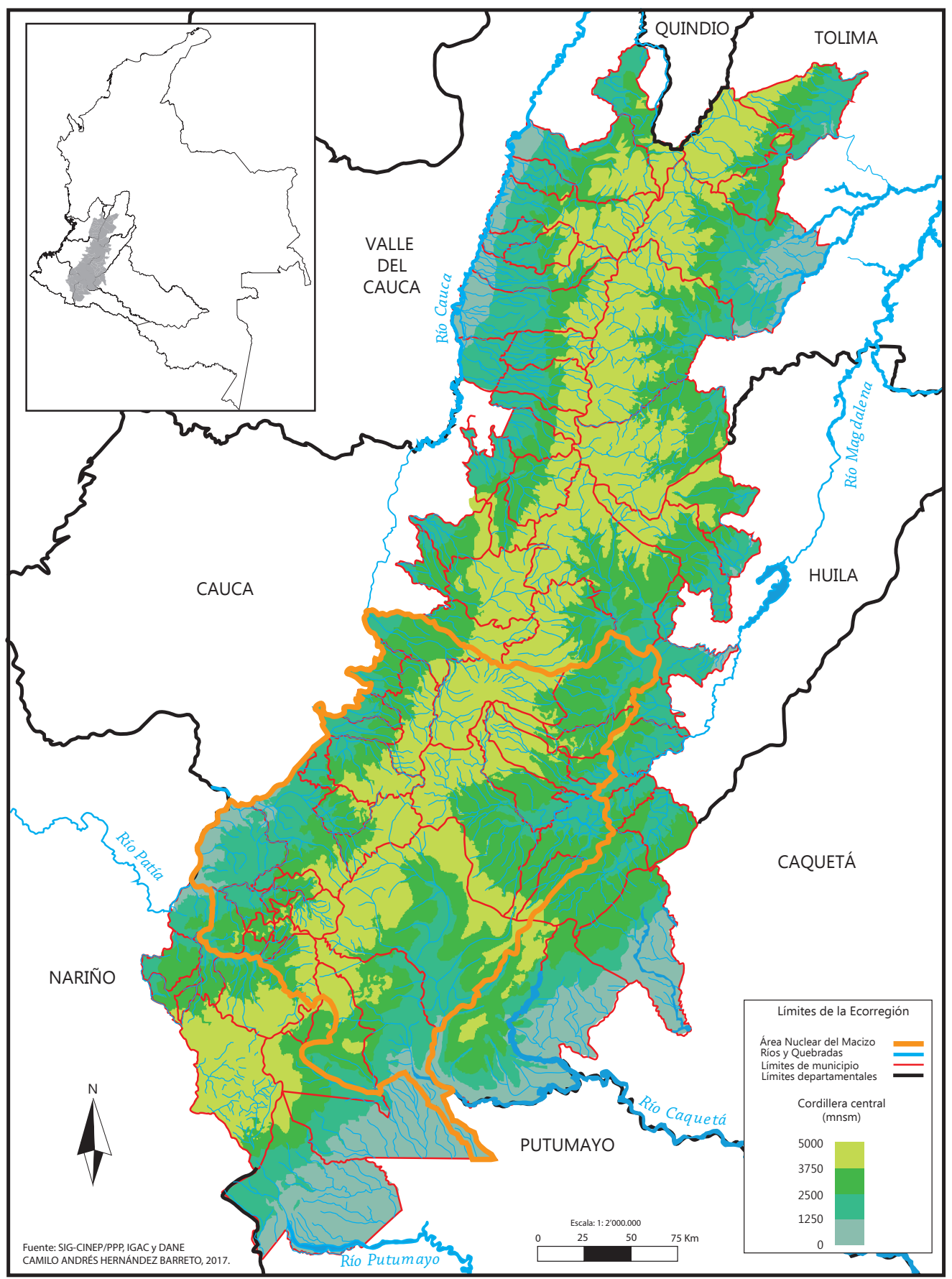

